\title{
BMJ Global Health Fighting non-communicable diseases in East Africa: assessing progress and identifying the next steps
}

Christian Kraef (D) ,1,2,3,4 Pamela A Juma, ${ }^{5,6}$ Joseph Mucumbitsi, ${ }^{4,7,8}$

Kaushik Ramaiya, ${ }^{4,9,10}$ Francois Ndikumwenayo, ${ }^{4,11,12}$ Per Kallestrup, ${ }^{1,3,4}$

Gerald Yonga ${ }^{4,6,13}$

To cite: Kraef C, Juma PA, Mucumbitsi J, et al. Fighting non-communicable diseases in East Africa: assessing progress and identifying the next steps. BMJ Global Health 2020;5:e003325. doi:10.1136/ bmjgh-2020-003325

Handling editor Seye Abimbola

Received 2 July 2020

Revised 20 September 2020

Accepted 17 0ctober 2020
Check for updates

(c) Author(s) (or their employer(s)) 2020. Re-use permitted under CC BY-NC. No commercial re-use. See rights and permissions. Published by BMJ.

For numbered affiliations see end of article.

Correspondence to Dr Christian Kraef; christiankraef@gmail.com

\section{ABSTRACT}

Sub-Saharan Africa has seen a rapid increase in noncommunicable disease (NCD) burden over the last decades. The East African Community (EAC) comprises Burundi, Rwanda, Kenya, Tanzania, South Sudan and Uganda, with a population of 177 million. In those countries, $40 \%$ of deaths in 2015 were attributable to NCDs. We review the status of the NCD response in the countries of the EAC based on the available monitoring tools, the WHO NCD progress monitors in 2017 and 2020 and the East African NCD Alliance benchmark survey in 2017. In the EAC, modest progress in governance, prevention of risk factors, monitoring, surveillance and evaluation of health systems can be observed. Many policies exist on paper, implementation and healthcare are weak and there are large regional and subnational differences. Enhanced efforts by regional and national policy-makers, non-governmental organisations and other stakeholders are needed to ensure future NCD policies and implementation improvements.

\section{SUB-SAHARA AFRICA AND NON-COMMUNICABLE DISEASES}

Sub-Saharan Africa has seen a rapid increase in non-communicable diseases (NCDs) over the last decades. Between 1990 and 2017, the proportion of all disability adjusted live years attributable to NCDs raised from 19\% to $30 \%$ of the total burden. ${ }^{1}$ On this trajectory, NCDs are set to overtake communicable, maternal, neonatal and nutritional conditions and diseases as cause of mortality by 2030 and are causing the so-called double burden of disease. ${ }^{2}$ In the countries of the East African Community (EAC) which comprises the countries Burundi, Rwanda, Kenya, Tanzania, South Sudan and Uganda with a population of 177 million, $40 \%$ of all deaths are currently attributable to $\mathrm{NCDs}^{3}$ (figure 1). In addition to the five major NCDs (cardiovascular diseases, cancers, respiratory diseases, mental illness and diabetes), other non-communicable conditions like sickle cell

\section{Summary box}

- The countries of the East African Community (EAC) have seen a rapid increase in non-communicable disease (NCD) burden over the last two decades.

- The status of the policy response to NCDs in the countries of the EAC can be assessed by comparing the WHO NCD progress monitors in 2017 and 2020 and the East African NCD Alliance benchmark surveys in 2014 and 2017.

- The monitoring tools describe notable progress in governance, risk factor prevention, surveillance and health system evaluation over the last 6 years.

- Many policies, however, only exist on paper and implementation is uneven across the region.

- Primary Healthcare Systems strengthening, civil society involvement and regional coordination need to be enhanced to accelerate progress.

disease, mental illness, injuries and disabilities are highly prevalent in East Africa.

A fairly consistent body of evidence has linked the rising burden of NCDs to several factors including globalisation of trade, rapid unplanned urbanisation, changes in nutrition, demography and environmental factors including climate change and air pollution. ${ }^{4}$ These risk factors are becoming increasingly prevalent and are well underway to accelerate the burden of NCDs in East Africa. ${ }^{5}$ Improved survival of people living with HIV (PLWH) drives the persistently high prevalence of HIV infections which is adding further complexity as NCDs are increasingly co-occurring in patients with HIV and an ageing population of PLWH. ${ }^{6}$ PLWH are at higher risk for diabetes and coronary artery diseases, compared with the general population, requiring better integration and coordination of care of NCDs and HIV. ${ }^{7}$ The need to integrate health systems and NCD-related care for patients with communicable diseases has recently also been underlined by the 
$\%$ of deaths attributable to NCDs in East Africa

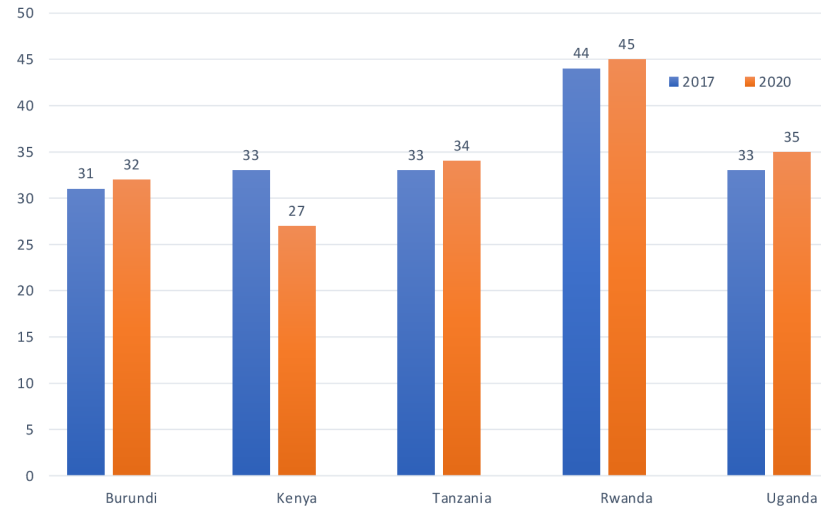

Figure 1 Percentage of all deaths attributable to noncommunicable diseases (NCDs) in countries of the East African Community (data from the WHO NCD progress monitors 2017 and 2020).

COVID-19 pandemic. $^{8}$ NCDs are major risk factors for patients with COVID-19, while some of the restrictive measures such as lockdowns reduce the level of physical activity, availability of healthy food and access to healthcare services which all are critical for patients with NCDs. ${ }^{9}$

\section{UNEVEN GLOBAL PROGRESS—AND EAST AFRICA FALLING BEHIND}

On a global scale, NCDs have become a priority since 2008 when the WHO's World Health Statistics highlighted the global shift in disease burden from communicable to NCDs. Furthermore, the 2008-2013 Action Plan for the Global Strategy for the Prevention and Control of NCDs was released. ${ }^{10}{ }^{11}$ In 2011, the United Nations (UN) held their first high-level meeting on NCDs with subsequent meetings in July 2014 and most recently in September 2018.

Worldwide, there has been a substantial reduction in premature mortality from NCDs between 2008 and 2018, but progress is uneven across populations which influenced the 2018 UN High Level Meeting Political Declaration on NCDs to call for renewed commitments of governments and a new UN HLM in $2025 .{ }^{12}$ The countries of the EAC are among those with raising NCD

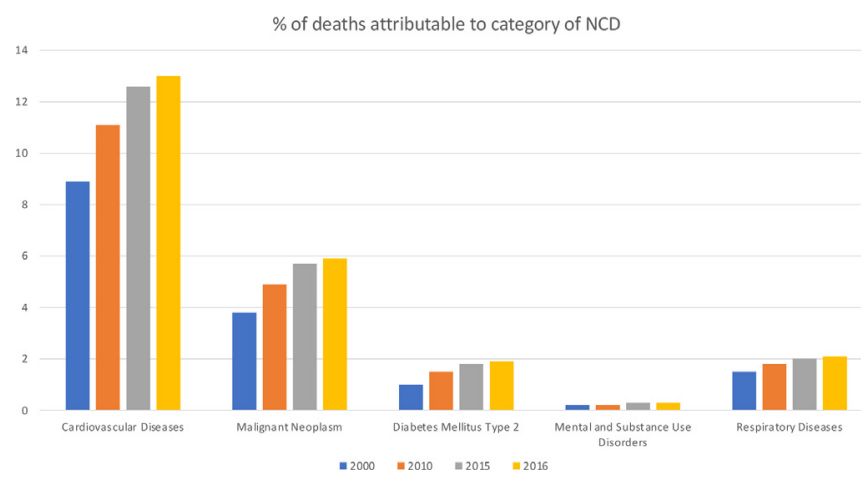

Figure 2 Trends in percentage of all deaths attributable to category of non-communicable diseases (NCDs) in countries of the East African Community (2000-2016). related mortality globally (figure 2). ${ }^{313} 14$ However, only few structured discussions of the NCD policy response in the region exist in the peer-reviewed literature. ${ }^{3}$ In 2015 , a group of researchers and civil society representatives published an analysis of the policy progress in fighting NCDs in the EAC where gaps in healthcare infrastructure, lack of guidelines, deficiencies in research and medical training and weak public health initiatives were named as barriers to progress. ${ }^{3}$ The authors called for better collaboration among EAC governments and civil society in addressing NCDs and they highlighted the advantages of a robust primary healthcare system and public health response which also addresses the social determinants of health. ${ }^{3}$ Civil society has played an increasing role in the NCD response in the EAC. ${ }^{15}$ The East Africa NCD Alliance Initiative, which unites the NCD alliances in Uganda, Tanzania, Zanzibar, Kenya, Burundi and Rwanda, has among other things committed itself to measure progress on NCD policy by conducting benchmark surveys in 2014 and 2017. ${ }^{15}$ South Sudan has joined the EAC in April 2016 but no civil society organisation has joined the East African NCD (EANCD) this far. Further information is available through the WHO's NCD progress monitors which were published in 2017 and 2020.

In this article, we review the status of the NCD policy response by governments in the countries of the EAC by compiling the results of the WHO NCD progress monitor from 2017 and 2020, as well as the East African NCD Alliance benchmark surveys in 2014 and 2017. Subsequently, we line out recommendations for the next steps for the NCD response in East Africa.

\section{THE CURRENT BURDEN OF NCDS IN EAST AFRICA}

According to the WHO disease burden and mortality estimates, the proportion of all deaths in the WHO Africa region that are attributable to NCDs increased from $22.8 \%$ (2.2 million) in the year 2000 to $34.2 \%$ (3.0 million) in the year $2016 .{ }^{14}$ In Kenya, $27 \%$ of all deaths are attributable to NCDs, followed by Burundi (32\%), Rwanda (33\%), Uganda (33\%) and Tanzania (44\%). Cardiovascular diseases caused $13 \%$ of all NCDrelated deaths, followed by malignant neoplasms (5.9\%), respiratory diseases $(2.1 \%)$ and diabetes mellitus $(1.9 \%)$ (figure 2). The most important NCD risk factors are high blood pressure, unhealthy diet, air pollution, high body mass index, tobacco use, alcohol and drug abuse, high fasting plasma glucose, high total cholesterol, and low physical activity, and have been shown to be rising significantly in Africa. ${ }^{16}$

\section{METHODOLOGY OF WHO NCD PROGRESS MONITOR AND THE EANCDA BENCHMARK SURVEY}

Two systematic assessments of the NCD response in EAC exist. The WHO NCDs progress monitors chart the actions of individual countries to set targets, implement policies and build capacities to reduce and treat 
NCDs and four main shared and modifiable NCD risk factors (tobacco, unhealthy diet, physical inactivity and harmful use of alcohol). ${ }^{14}$ Their objective is to report on the progress achieved in the implementation of national commitments included in the 2011 UN Political Declaration and the 2014 UN Outcome Document on NCDs. They have been conducted in 2017 and 2020. The data were collected by the WHO. Assessment of the indicators national NCD targets; risk factor surveys; integrated NCD policy; unhealthy diet; public education; guidelines for management and drug therapy were taken from WHO Member State responses to the 2019 NCD Country Capacity Survey which was completed as an online web-based survey by NCD focal points within ministries of health (or similar national agencies). Countries were required to provide supporting documentation to enable review by WHO. Assessment of the indicator related to availability of mortality data was based on an assessment of the WHO mortality database. The indicator for harmful use of alcohol reduction measures was based on the responses of country focal points responsible for the 2019 global survey on progress on SDG health target 3.5 nominated by each ministry of health. Assessment of the indicator for tobacco demand reduction measures was based on data collected from member states in 2019 for the production of the WHO Report on the Global Tobacco Epidemic. Member states were given the opportunity to review all data that had been collected before publication of the report. For our study, we extracted the data from the country profiles of the published report available on the WHO website. ${ }^{14}$

Further, the East African NCD Alliance (EANCDA), a civil society organisation which represents the national NCD Alliances in member states of the EAC, has twice conducted a benchmark survey, which was based on the revised Global NCD Alliance benchmarking survey tool and adapted to the East African context. ${ }^{17}$ The tool is structured around the four objectives of the WHO Global NCD Action Plan 2013-2020. The Action Plan has as its priority themes: raising priority of NCDs through international cooperation and advocacy; strengthening national capacity, multisectoral action, and partnerships for NCDs; reducing NCD risk factors and social determinants; strengthening and reorienting health systems to address NCDs; promoting national capacity for research and development on NCDs; and monitor and evaluate progress on NCDs. The data were collected from all six East African countries participating in the EANCDA. The sampling of key informants was purposive. The survey data were collected through reviews of 46 national level NCD related policy documents and 28 key informant interviews with relevant NCD programme leads as well as other relevant stakeholders in the countries. Data were collected by the national and regional NCD alliances and compiled in final reports for review of NCD civil society stakeholders ${ }^{18}$ and researchers from East Africa before publication. ${ }^{141718}$
RESULTS OF THE LATEST WHO NCD PROGRESS MONITOR 2020 FOR COUNTRIES OF THE EAC

According to the WHO NCD progress monitors, all EAC countries $(n=5)$ have introduced national NCDmanagement guidelines, all have partially introduced alcohol and tobacco policies, four (except Burundi) have at least partially conducted risk factor surveys. Three (Kenya, Tanzania and Burundi) have set national NCD targets and a national integrated NCD policy/strategy/ action plan. Public education and awareness campaigns on physical activity have only been conducted in Uganda and Rwanda. However, no country has achieved the targets for mortality data public education and awareness campaigns on physical activity or drug therapy/counselling to prevent heart attacks and strokes (table 1). Tanzania has at least partially achieved 7 (of a total of 10) targets, followed by Kenya (6/10), Uganda, Rwanda and Burundi (5/10 each).

\section{RESULTS OF THE EANCDA BENCHMARK SURVEY 2017}

The NCD benchmarking survey 2017-as a follow-up to the survey carried out in 2014-focused on the four themes governance; prevention and reduction of risk factors; monitoring, surveillance and evaluation and health systems readiness (table 2).

For the Governance domain, the survey authors reported progress in prioritising NCDs at national levels. Most of the recent health sector strategic plans were reported to include NCDs as one of their national priority areas. All other countries, apart from Burundi, Uganda and Rwanda had operational national NCD strategic/action plans. However, implementation of the plans was weak due to low financial resources allocation as well as inadequate human resource capacity. NCD units have been established in all the countries to coordinate policy development and stakeholder engagement in implementation of NCD interventions. Some units were still understaffed and lacked funds for daily operations. Multisectoral action and coordination mechanisms in NCD prevention were still found inadequate. Only Zanzibar and Uganda had established multisectoral committees for NCD prevention and control. Civil society engagement in NCD prevention was found to be increasing. There were sufficiently funded NGOs that are implementing some NCD prevention and care interventions. National NCD alliances existed in all countries and they worked closely with the Ministries of Health. However, the engagement was not well structured and coordinated. Some of the alliances faced financial and leadership challenges that have to be addressed.

In the second domain, Prevention and Reduction of Risk Factors, all countries apart from Burundi had ratified the WHO Framework Convention on Tobacco Control. All countries, apart from Burundi and Tanzania had tobacco control legislation in place. There had been little progress in implementing alcohol control interventions in most of the countries; only Kenya and Rwanda 
Table 1 WHO non-communicable diseases (NCD) progress monitor for East African community (2017/2020)

\begin{tabular}{|c|c|c|c|c|c|}
\hline Indicator & Kenya & $\begin{array}{l}\text { Tanzania (incl. } \\
\text { Zanzibar) }\end{array}$ & Uganda & Rwanda & Burundi \\
\hline National NCD targets & O/O & /० & ০/० & ০/० & /० \\
\hline Mortality data & ০/০ & ০/০ & ০/০ & ০/০ & ০/০ \\
\hline Risk factor surveys & O/O & $\mathbf{0} / \mathbf{0}$ & O/O & $\mathbf{0} / \mathbf{0}$ & ০/० \\
\hline $\begin{array}{l}\text { National integrated NCD policy/strategy/ } \\
\text { action plan }\end{array}$ & O/O & ๑/○ & ০/০ & ০/০ & $\circ / \bigcirc$ \\
\hline Tobacco demand-reduction measures & $\mathbf{0} / \mathbf{0}$ & ০/0 & $\mathbf{0} / \mathbf{0}$ & $\mathbf{0} / \mathbf{0}$ & o/0 \\
\hline $\begin{array}{l}\text { Harmful use of alcohol reduction } \\
\text { measures }\end{array}$ & $\mathbf{0} / \mathbf{0}$ & $\mathbf{0} / \mathbf{0}$ & $\mathbf{0} / \mathbf{0}$ & $\mathbf{0} / \mathbf{0}$ & $\mathbf{0} / \mathbf{0}$ \\
\hline Unhealthy diet reduction measures & ০/० & $\mathbf{0} / \mathbf{0}$ & ০/० & ০/० & ০/० \\
\hline $\begin{array}{l}\text { Public education and awareness } \\
\text { campaign on physical activity }\end{array}$ & ০/০ & ০/০ & $\circ / \bigcirc$ & $\circ / \bigcirc$ & ০/० \\
\hline $\begin{array}{l}\text { Guidelines for management of cancer, } \\
\text { CVD, diabetes and chronic respiratory } \\
\text { disease }\end{array}$ & $\mathbf{0} / 0$ & $\circ / 0$ & $\mathrm{O} / 0$ & \%/0 & $\mathbf{0} / \mathbf{0}$ \\
\hline $\begin{array}{l}\text { Drug therapy/counselling to prevent heart } \\
\text { attacks and strokes }\end{array}$ & ০/० & ০/০ & ০/০ & ০/০ & ০/০ \\
\hline
\end{tabular}

$\mathbf{O}=$ fully achieved $\boldsymbol{O}=$ partially achieved $\mathrm{o}=$ not achieved. NCD Progress Monitor, 2017/2020. Geneva WHO; 2017/2020.

CVD, cardiovascular diseases.

had comprehensive alcohol control acts that address the 'WHO best buy interventions' for alcohol control. All countries apart from Zanzibar and Burundi have developed nutrition action plans, but they were often lacking in addressing NCD-related issues and interventions. None of the countries had legislation or regulatory policies on marketing foods high in sugars and fats or salt reduction. National policies and strategies to address physical activity did not exist, except for the physical education guidelines in schools. Even for schools there was no strict follow-up by governments to ensure that these guidelines were implemented.

For the third domain, health systems, the survey found the quality of NCD services still to be poor in the public healthcare facilities due to inadequate infrastructure, financial resource allocation and commodities and supplies. Primary healthcare facilities still lacked the capacity to provide effective NCD preventive and care services except in Rwanda where there were ongoing strategies for integrated NCD primary care. There were inadequate numbers of trained health professionals to manage and control NCDs at the primary care level. Most of the public health facilities lacked various specialist and high-level diagnostic equipment. In most countries, NCD management guidelines had been developed for some NCDs but were not adequately disseminated and implemented. Thus, many patients tended to seek care from the few costly private facilities or abroad.

In the fourth domain, Monitoring, Surveillance and Evaluation, all the countries apart from Burundi had set up some mechanism to undertake periodic surveillance of NCDs and their risk factors. Tanzania, Rwanda, Kenya and Uganda had completed STEPS surveys since 2013, but not Burundi.

On international reporting, most of the countries had been reporting on NCD prevalence, mortality and morbidity as well as risk factors exposure to the WHO progress monitoring framework. Generally, countries had not established strong national information systems with surveillance mechanisms that monitor key risk factors, morbidity and mortality and health-system capacity for NCDs. Most governments had not set up NCD research priorities or set aside funding for NCD research. Some NCD research was going on in some countries through academic and research institutions.

\section{ONLY WEAK REPORTS OF PROGRESS BETWEEN 2014 AND 2017}

In comparison to the first benchmark survey (2014) in the East African countries, there has been some progress in prioritising NCDs. Two countries (Tanzania and Kenya) had launched their NCD strategic plans. There are also improvements in NCD coordination in the health sector by strengthening of NCD units including some increase in number of staff. The health sector related progress has also comprised the development of care guidelines for various NCD conditions (including training manuals for healthcare workers in Zanzibar, Kenya and Tanzania).

For the WHO NCD progress monitor, only very limited development compared with the monitoring in 2017 can be reported. Tanzania and Burundi have at least partially achieved two additional targets, while Uganda and Rwanda have achieved one additional target. Progress has in particular been reported for tobacco 
Table 2 Results of the East African Non-Communicable Diseases (NCD) Alliance Benchmark Survey (2017)

\begin{tabular}{|c|c|c|c|c|c|c|}
\hline & Burundi & Kenya & Uganda & Rwanda & Tanzania & Zanzibar \\
\hline \multicolumn{7}{|l|}{ 1) Governance } \\
\hline NCDs included in the national development plan & ० & ○ & ○ & 0 & ○ & 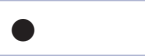 \\
\hline NCDs included in national health sector plan & 0 & 0 & 0 & 0 & 0 & 0 \\
\hline NCD strategy/action plan available & $\circ$ & ○ & $\circ$ & $\circ$ & ○ & ○ \\
\hline Presence of NCD targets/indicators & $\circ$ & 0 & $\circ$ & $\circ$ & 0 & 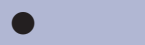 \\
\hline Dedicated NCD department & 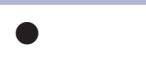 & 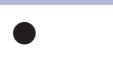 & $\bullet$ & 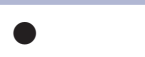 & 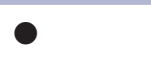 & 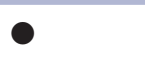 \\
\hline National multisectoral commission/agency & $\circ$ & $\circ$ & 0 & $\circ$ & $\circ$ & O \\
\hline Formal Government systems to engage Civil Society & o & $\mathbf{0}$ & $\bullet$ & ○ & ○ & 0 \\
\hline Government engagement of PLWNCDs & ○ & - & ○ & $\circ$ & $\circ$ & $\circ$ \\
\hline $\begin{array}{l}\text { Public-private partnerships to improve NCD prevention } \\
\text { and control. }\end{array}$ & $\circ$ & ० & ० & 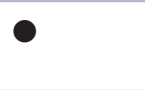 & ० & ○ \\
\hline \multicolumn{7}{|l|}{ 2) Prevention and reduction of risk factors } \\
\hline Tobacco Legislation & ○ & $\bullet$ & $\bullet$ & $\bullet$ & ○ & $\bullet$ \\
\hline $\begin{array}{l}\text { Tobacco legislation on pack labelling and pictorial } \\
\text { health warnings }\end{array}$ & ○ & $\bullet$ & $\bullet$ & $\bullet$ & o & $\bullet$ \\
\hline Tobacco taxation policy & o & $\mathbf{0}$ & ○ & $\mathbf{0}$ & ○ & ० \\
\hline Smoke free public policy & 0 & $\bullet$ & $\bullet$ & $\circ$ & $\circ$ & $\bullet$ \\
\hline Bans on tobacco advertising and sponsorship & ० & 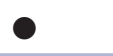 & $\bullet$ & $\circ$ & $\circ$ & ○ \\
\hline Comprehensive alcohol control Legislation & ० & $\bullet$ & 0 & $\bullet$ & 0 & - \\
\hline Special tax on alcohol & ० & $\bullet$ & $\circ$ & $\circ$ & $\circ$ & $\circ$ \\
\hline Taxation for domestic brew & 0 & 0 & 0 & 0 & 0 & o \\
\hline Restriction on alcohol advertising & $\circ$ & - & $\circ$ & $\circ$ & $\circ$ & $\bullet$ \\
\hline Regulation to control access to alcohol & ० & $\circ$ & $\bullet$ & 0 & 0 & ० \\
\hline $\begin{array}{l}\text { Restrictions on times and dates at which alcohol can } \\
\text { be purchased }\end{array}$ & ० & $\bullet$ & ० & ० & ० & ○ \\
\hline $\begin{array}{l}\text { Restrictions in place government legislated, } \\
\text { coregulations, or self-regulated by industry }\end{array}$ & o & ० & o & 0 & 0 & 0 \\
\hline Licensing system for retailers & $\circ$ & $\bullet$ & $\bullet$ & $\bullet$ & $\bullet$ & $\bullet$ \\
\hline National drink driving law & 0 & $\bullet$ & $\bullet$ & $\bullet$ & $\bullet$ & \\
\hline $\begin{array}{l}\text { Regulations that address different types of media, } \\
\text { format, times and traditional and digital media }\end{array}$ & $\circ$ & $\bullet$ & $\circ$ & $\circ$ & • & $\circ$ \\
\hline $\begin{array}{l}\text { Established minimum age for purchase and } \\
\text { consumption }\end{array}$ & 0 & • & • & • & $\bullet$ & $\bullet$ \\
\hline
\end{tabular}

\section{3) Health systems readiness}

\begin{tabular}{|c|c|c|c|c|c|c|}
\hline $\begin{array}{l}\text { National guidelines/protocols for management of major } \\
\text { NCDs }\end{array}$ & - & - & 0 & 0 & 0 & - \\
\hline Guidelines for mental and neurological disorders & ० & $\bullet$ & $\circ$ & $\bullet$ & $\bullet$ & ○ \\
\hline Guidelines for tobacco dependence treatment & 0 & $\bullet$ & 0 & 0 & $\circ$ & $\circ$ \\
\hline Guidelines for alcohol dependence treatment & ० & $\bullet$ & $\circ$ & $\mathbf{0}$ & ○ & ○ \\
\hline $\begin{array}{l}\text { Government initiatives delivering NCD detection, } \\
\text { treatment and care }\end{array}$ & D & $\bullet$ & $\bullet$ & $\bullet$ & $\bullet$ & $\bullet$ \\
\hline Updated national essential medicines list & $\circ$ & $\bullet$ & $\bullet$ & $\bullet$ & $\bullet$ & - \\
\hline $\begin{array}{l}\text { Standards for availability/affordability of NCD essential } \\
\text { medicines/technologies }\end{array}$ & $\circ$ & $\bullet$ & $\bullet$ & $\bullet$ & $\bullet$ & $\circ$ \\
\hline $\begin{array}{l}\text { Studies published on availability/affordability of } \\
\text { essential medicines and technologies }\end{array}$ & $\circ$ & $\circ$ & $\circ$ & $\circ$ & ○ & ○ \\
\hline
\end{tabular}

Continued 
Table 2 Continued

\begin{tabular}{|c|c|c|c|c|c|c|}
\hline & Burundi & Kenya & Uganda & Rwanda & Tanzania & Zanzibar \\
\hline $\begin{array}{l}\text { NCD prevention and management integrated into } \\
\text { training programmes for healthcare professionals }\end{array}$ & ○ & D & $\bullet$ & $\bullet$ & $\bullet$ & $\bullet$ \\
\hline
\end{tabular}

4) Monitoring, surveillance and evaluation

Periodic surveillance on NCDs
$\begin{aligned} & \text { National STEPwise approach to Surveillance (STEPS) } \\ & \text { survey done }\end{aligned}$

$\boldsymbol{\bullet}=$ fully achieved $\boldsymbol{O}=$ partially achieved $\mathrm{o}=$ not achieved.

NCD Benchmark Survey in East African Countries, East African NCD Alliance 2017.

PLWNCD, people living with NCDs.

demand-reduction measures and education and awareness campaigns on physical activity.

\section{COMPARING THE NCD WHO PROGRESS MONITOR AND THE CIVIL SOCIETY BENCHMARKING REPORTS}

Kenya is leading in both assessments while Burundi has the weakest NCD policy response in both. Tanzania can also report a robust policy response in both assessments but is falling behind on the prevention and reduction of risk factors domain in the NCD alliance benchmark survey. Uganda and Rwanda both report some progress in both assessments and can be ranked in the middle in the EAC.

The WHO progress report highlights severe gaps in leadership, investment, care, community engagement and accountability. It has been interpreted as a clear message that political commitment and pledges alone are not sufficient and must be accompanied by highlevel strategic leadership and governance. ${ }^{19}$ The inference of alcohol, food and beverages industries in the policy-making decisions has been highlighted as a major obstacle to progress. ${ }^{19}$ The NCD Benchmark surveys have observed notable progress in governance; prevention and reduction of risk factors; monitoring, surveillance and evaluation and health systems strengthening for NCD prevention and management in all countries of the EAC. But the survey report is impeded by three important caveats. First, this progress has been very unevenly distributed across the EAC countries. Second, for some indicators, no or very little progress can be reported. Three, there is inadequate data on the degree of implementation of the policies and their impacts on the population. While some laws, regulations and guidelines do exist in theory, their enactment can vary considerably within countries and populations.

\section{EANCDA POLICY RECOMMENDATIONS BASED ON THE BENCHMARK SURVEY}

The East African NCD Alliance has in the NCD benchmark surveys highlighted a number of recommendations to tackle these challenges. ${ }^{18}$ These recommendations include for countries to prioritise the NCDs agenda in the health development plans and fully implementing tobacco, alcohol, unhealthy food and physical activity legislations and policies recommended by the WHO. Furthermore, EAC countries should institutionalise national multisectoral coordination mechanisms for NCDs and provide more financial resources for the health sector and in particular NCD programmes to reach the $15 \%$ national budget target for health imparted by the Abuja declaration. The main delivery method for NCD care packages should be through primary health care-based services, supported by service delivery guidelines. Revenues for the health sector can be generated by fully implementing taxation of alcohol, tobacco and unhealthy food and drinks. Strengthened NCD monitoring and evaluation systems and frameworks, including health information systems to monitor NCD morbidity, mortality and risk factors require increased attention. Further priorities should be a more favourable environment for civil society and organisations of people living with NCDs (PLWNCDs) and increased funding for 


\section{Box 1 Summary of important next steps}

- Strong civil society movement based on a human rights platform.

- Tax-based universal health coverage.

- Integrated primary healthcare systems that provide care for communicable and non-communicable diseases and comorbidities.

- Regional coordination for integration of policies and laws (ie, tobacco and alcohol taxation, road traffic injuries prevention).

- Increased availability of local evidence-based data to inform policy development, monitoring and evaluation.

- Continued establishment of regional NCD training, specialised care and research driven centres of excellence.

research that can help to inform NCD policies and strategic plans.

\section{THE BROADER PICTURE: WHAT ARE THE NEXT STEPS FOR FIGHTING NCDS IN EAST AFRICA?}

To ensure future NCD policies development and implementation improvements, a strong human right-based civil society involving PLWNCDs, established Universal Health Coverage and focus on primary healthcare strengthening are central (box 1). Historically, strong civil society movements have been able to accelerate public health policy and access to healthcare based on a human rights platform. This has successfully been demonstrated by the HIV/AIDS movement, and more recently the maternal and child health agenda. ${ }^{20}{ }^{21}$ Highlighting the health impacts of climate change and air pollution, which will particularly exacerbate mortality and morbidity in PLWNDs, should become part of this public discourse. The climate crisis is a health crisis and prevention and treatment of NCDs will make societies more resilient to climate change while climate change mitigation and adaption efforts can effectively create health cobenefits. ${ }^{22}$

A major impediment to improved NCD prevention, diagnosis and management are financing challenges for primary and specialised care. To ensure sufficiently funded health systems that are free at the point of care (tax-based), universal health coverage needs to be implemented in the countries of the EAC. One established approach to raise revenues for health is the 'sin-tax' approach on tobacco, alcohol and sugary drinks. ${ }^{23}$ The EAC and its member states should consider the cobenefits of raising resources for universal health coverage while ensuring large population-level health promotion.

The programmatic motor of UHC is primary healthcare, which has been underfunded and understaffed in most countries of the East African region. Strengthening primary healthcare structures and integrating specific programmes (eg, HIV/AIDS programmes) has previously been highlighted as an effective approach to prevention, diagnosis and treatment of NCDs. ${ }^{24}$ Due to its holistic nature, community focus, and core values, primary healthcare is cost effective and it aligns well with the needs of the NCD health threat, reflecting the epidemiology and challenges of chronic conditions. ${ }^{25} 26$ Furthermore, primary healthcare is an established platform to integrate NCDs and infectious diseases like HIV care and treatment. ${ }^{27}$ Primary healthcare strengthening has been made a priority health development objective again in various forums including the Astana conference in $2018 .^{28}$ This development provides opportunities for additional political attention, a push for additional scientific evidence and economic resources from official development assistance and other donors.

Generally, regional coordination among the member states of the EAC for integration of policies around common challenges and laws for tobacco and alcohol taxation, road traffic injuries prevention, and the provision of preventive, curative and rehabilitative care for NCDs is highly needed. This will help ensure sustainable high-quality and high-impact policies. Lastly, there is need to improve the availability of local evidence-based data to inform policy development, monitoring and evaluation. This can be achieved by integrating NCDs and risk factors indicators into national periodical health surveys and established health information and surveillance systems. In addition, the ongoing establishment of regional NCD training, specialised care and research driven centres of excellence at Kenya, Uganda, Rwanda, Tanzania and Burundi Universities is expected to boost affordable, quality and accredited skills, tertiary institutions and services in biomedical sciences and support research to measure the impact of different NCD prevention and control policies at regional and national levels. ${ }^{29}$

\section{Author affiliations}

${ }^{1}$ Centre for Global Health, Department of Public Health, Aarhus University, Aarhus, Denmark

${ }^{2}$ Heidelberg Institute of Global Health (HIGH), University of Heidelberg, Heidelberg, Germany

${ }^{3}$ Danish NCD Alliance, Copenhagen, Denmark

${ }^{4}$ East Africa NCD Alliance, Kampala, Uganda

${ }^{5}$ African Population and Health Research Center, Nairobi, Kenya

${ }^{6} \mathrm{NCD}$ Alliance Kenya, Nairobi, Kenya

${ }^{7}$ College of Medicine and Health Sciences, University of Rwanda, Kigali, Rwanda

${ }^{8}$ Rwanda NCD Alliance, Kigali, Rwanda

${ }^{9}$ Shree Hindu Mandal Hospital, Dar es Salaam, United Republic of Tanzania

${ }^{10}$ Tanzania NCD Alliance, Dar es Salaam, United Republic of Tanzania

${ }^{11}$ University of Burundi, Bujumbura, Bujumbura Mairie Province, Burundi

${ }^{12}$ Burundi NCD Alliance, Bujumbura, Burundi

${ }^{13}$ University of Nairobi, Nairobi, Kenya

Contributors All authors contributed to conception and design of the article. JP and CK collected the data. CK, PAJ, JM, and PK drafted the manuscript. All authors critically revised the manuscript and gave final approval.

Funding The authors have not declared a specific grant for this research from any funding agency in the public, commercial or not-for-profit sectors.

Competing interests None declared.

Patient consent for publication Not required.

Provenance and peer review Not commissioned; externally peer reviewed.

Data availability statement All data relevant to the study are included in the article.

Open access This is an open access article distributed in accordance with the Creative Commons Attribution Non Commercial (CC BY-NC 4.0) license, which permits others to distribute, remix, adapt, build upon this work non-commercially, 
and license their derivative works on different terms, provided the original work is properly cited, appropriate credit is given, any changes made indicated, and the use is non-commercial. See: http://creativecommons.org/licenses/by-nc/4.0/.

ORCID iD

Christian Kraef http://orcid.org/0000-0002-5224-0335

\section{REFERENCES}

1 Gouda HN, Charlson F, Sorsdahl K, et al. Burden of noncommunicable diseases in sub-Saharan Africa, 1990-2017: results from the global burden of disease study 2017. Lancet Glob Health 2019;7:e1375-87.

2 WHO | Regional Office for Africa. Noncommunicable Diseases [Internet]. Available: https://www.afro.who.int/health-topics/ noncommunicable-diseases [Accessed 19 Mar 2020].

3 Siddharthan T, Ramaiya K, Yonga G, et al. Noncommunicable diseases in East Africa: assessing the gaps in care and identifying opportunities for improvement. Health Aff 2015;34:1506-13.

4 Prüss-Ustün A, van Deventer E, Mudu P, et al. Environmental risks and non-communicable diseases. BMJ 2019;364:I265.

5 Miranda JJ, Barrientos-Gutiérrez T, Corvalan C, et al. Understanding the rise of cardiometabolic diseases in low- and middle-income countries. Nat Med 2019;25:1667-79.

6 Haacker M, Bärnighausen T, Atun R. Hiv and the growing health burden from noncommunicable diseases in Botswana: modelling study. J Glob Health 2019:9:010428.

7 Noubissi EC, Katte J-C, Sobngwi E. Diabetes and HIV. Curr Diab Rep 2018;18:125.

8 Kraef $C$, Juma $P$, Kallestrup $P$, et al. The COVID-19 pandemic and non-communicable Diseases-A wake-up call for primary health care system strengthening in sub-Saharan Africa. J Prim Care Community Health 2020;11:215013272094694.

9 Kluge HHP, Wickramasinghe K, Rippin HL, et al. Prevention and control of non-communicable diseases in the COVID-19 response. Lancet 2020;395:1678-80.

10 WHO. Noncommunicable diseases now biggest killers [Internet]. Available: https://www.who.int/mediacentre/news/releases/2008/ pr14/en/ [Accessed 13 Mar 2020].

11 WHO. 2008-2013 Action plan for the global strategy for the prevention and control of noncommunicable diseases [Internet]. Available: http://www.who.int/nmh/publications/9789241597418/en/ [Accessed 13 Mar 2020].

12 Alliance NCD. Summary Table of Commitments in the 2018 Political Declaration of the UN High-Level Meeting on NCDs [Internet], 2018. Available: https://ncdalliance.org/sites/default/files/resource files/ HLM3\%20on\%20NCDS_PD\%20Commitments\%20Summary\% 20Table_final.pdf [Accessed 27 Jun 2020].

13 Noncommunicable diseases progress monitor, 2020. Available: https://www.who.int/publications/i/item/ncd-progress-monitor-2020 [Accessed 8 Sep 2020].
14 World Health Organization. WHO NCDs Progress Monitor 2017 [Internet], 2017. Available: https://ncdalliance.org/resources/whoncds-progress-monitor-2017 [Accessed 9 May 2020].

15 NCD Alliance. East Africa NCD Alliance Initiative [Internet], 2014. Available: https://ncdalliance.org/east-africa-ncd-alliance-initiative [Accessed 17 Jun 2020].

16 GBD 2013 Risk Factors Collaborators, Forouzanfar $\mathrm{MH}$, Alexander $\mathrm{L}$, et al. Global, regional, and national comparative risk assessment of 79 behavioural, environmental and occupational, and metabolic risks or clusters of risks in 188 countries, 1990-2013: a systematic analysis for the global burden of disease study 2013. Lancet 2015;386:2287-323

17 NCD Alliance. A civil society benchmark report: Responses to NCDs in East Africa [Internet], 2014. Available: https://ncdalliance.org/ resources/a-civil-society-benchmark-report-responses-to-ncds-ineast-africa [Accessed 16 Jun 2020].

18 East African NCD Alliance. Non-communicable disease benchmark survey in East African countries, 2018.

19 The Lancet Diabetes Endocrinology. Ncd threat: falling on deaf ears. Lancet Diabetes Endocrinol 2020;8:257.

20 Sabi SC, Rieker M. The role of civil society in health policy making in South Africa: a review of the strategies adopted by the treatment action campaign. Afr J AIDS Res 2017;16:57-64.

21 Dunn JT, Lesyna K, Zaret $A$. The role of human rights litigation in improving access to reproductive health care and achieving reductions in maternal mortality. BMC Pregnancy Childbirth 2017; $17: 367$.

22 Rother H-A. Controlling and preventing climate-sensitive noncommunicable diseases in urban sub-Saharan Africa. Sci Total Environ 2020;722:137772.

23 Javadinasab H, Masoudi Asl I, Vosoogh-Moghaddam A, et al. Sustainable financing of health promotion services in selected countries: best experience for developing countries. Med J Islam Repub Iran 2019;33:52.

24 Juma K, Juma PA, Mohamed SF, et al. First Africa noncommunicable disease research conference 2017: sharing evidence and identifying research priorities. J Glob Health 2019;8:020301.

25 Demaio AR, Kragelund Nielsen K, Pinkowski Tersbøl B, et al. Primary health care: a strategic framework for the prevention and control of chronic non-communicable disease. Glob Health Action 2014;7:24504.

26 Contribution of Primary Care to Health Systems and Health PubMed [Internet]. Available: https://pubmed.ncbi.nlm.nih.gov/ 16202000/?from_term=Barbara+Starfield\&from_sort=date\&from page $=8 \&$ from pos $=2$ [Accessed 1 Jun 2020]

27 Duffy M, Ojikutu B, Andrian S, et al. Non-Communicable diseases and HIV care and treatment: models of integrated service delivery. Trop Med Int Health 2017;22:926-37.

28 Kraef C, Kallestrup P. After the Astana declaration: is comprehensive primary health care set for success this time? BMJ Glob Health 2019;4:e001871.

29 University World News. Four East Africa medical centres of excellence underway [Internet]. Available: https://www. universityworldnews.com/post.php?story=20151009080919608 [Accessed 28 Jun 2020]. 